\title{
The "What" and "Hows" of Mindfulness: Using DBT's Mindfulness Skills to Reduce Test Anxiety
}

\author{
John E. Lothes II, M.A., L.P.A. \\ University of North Carolina Wilmington \\ Kirk Mochrie \\ East Carolina University
}

\begin{abstract}
Background: Many studies have shown the positive effects of extended mindfulness interventions on anxiety reduction in several different populations; however, few have yet to examine the effects of mindfulness interventions on test anxiety in a college student population.

Aim: This study assesses the effects of overall test anxiety reduction through the use of Dialectical Behavior Therapy's (DBT's) mindfulness skills over an eight-week period among college students.

Methods: Participants included 16 college students that were trained in mindfulness, which included an eight-week mindfulness training using DBT's "What" and "How" skills of the mindfulness module. Participants were assessed on text anxiety, general anxiety, and mindfulness at the beginning, mid-way point, and end of the study. A weekly schedule of mindfulness practices was given to participants to complete on their own at home.

Results: Participants showed significant within-group reductions in test anxiety from the start of the study $(M e a n=56, S D=11.47)$ to the end of the study (Mean $=37.56, S D=9.98)$.

Conclusions: It is likely a mindfulness intervention that specifically teaches the "What" and "How" skills of DBT can help students reduce not only test anxiety, but overall anxiety, as well as increase individual levels of mindfulness based on the self-reported mindfulness questionnaire. Further research is needed to more definitively assess these results matched against a wait-list control group.
\end{abstract}

Submitted 21 August 2017: accepted 10 October 2017

Keywords: mindfulness, test anxiety, anxiety

Anxiety affects people both psychologically and physiologically and includes symptoms such as elevated heart rate, racing thoughts, increased perspiration, restlessness, and negative thinking and affect (Spielberger, 2010; Spielberger, \& Vagg, 1995). These symptoms illustrate that not all anxiety is externally present. For example, students in a classroom may appear calm while experiencing racing thoughts and negative self-talk occurring as an internal dialogue. Spielberger \& Vagg (1995) defines state anxiety as "an emotional state of fear, discomfort, nervousness, and an arousal of the autonomic nervous system, which is induced by a situation that presents a perception of danger or threat" (p. 6). Spielberger (1983) defines trait anxiety as anxiety that is an enduring personality characteristic to feel stress, worry and discomfort consistently across the lifespan. State and trait anxiety among individuals might manifest with similar symptoms; however, the maintaining factors a re clearly different. It is likely students may experience a combination of these anxiety types; more specifically, test anxiety. 
Many students may experience anxiety while taking tests; however, this does not necessarily constitute full-blown test anxiety. Test anxiety as defined by Duesek (1980) is " an emotional state that has psychological and behavioral concomitants, and that is experienced in formal testing or other evaluative situations" (p. 88). Sarason (1984) explains test anxiety as " A widely studied personality variable in part because it provides a measure of the personal salience of one important definable class of threating situations in which people are evaluated" (p. 292). Speilberger and Vagg (1995) have explained test anxiety as being comprised of cognitive attention processes that interfere with students' academic situations, performance and examinations. Zeinder(1998) describes test anxiety as being comprised of a set of phenomenological, physiological and behavioral responses that are accompanied by worries about possible negative outcomes or failures on a test or some type of similar evaluative experience. These interpretations diligently describe the tumultuous nature of the experience of test anxiety for individuals. As the number of students who enter college and obtain degrees increases, the impact of anxiety on college students is of concern.

Research demonstrates that test anxiety can have adverse and debilitating effects on test scores and academic performance among college students (Vitasari, Wahab, Othman, Herawan, Sinnadurai, 2010; Sarason \& Stoops, 1978). These individuals may be at risk for various negative outcomes related to anxiety symptoms including poor academic performance and higher dropout rates (Lang \& Lang, 2010). For example, Vitasari et al. (2010) found that test anxiety leads to passive attitudes in students' studies such as lack of interest in learning and poor academic performance on exams and assignments.

The potential impact that test anxiety could have on academic performance may present unique challenges for the college student population. Vitasari et al. (2010) found a relationship between college students with high anxiety and academic performance among engineering students $(N=205, F=109, M=96)$ through the University of Malaysia Pahang (UMP), with students exhibiting higher levels of anxiety having poorer academic performance overall. The relationship between anxiety and academic performance, if not properly addressed, could have long standing detrimental effects on college students' academic a chievement, which might negatively interfere with other areas of life functioning. For example, studies have shown that negative outcomes related to anxiety among students, including, self-medicating behaviors that may lead to addiction (Tektas, Paulsen, \& Sel, 2013).

It is well known that general symptoms of anxiety are related to problems in functioning including academic performance among college students; but what about test anxiety? Some research has specifically examined the negative impact of test anxiety on college student academic functioning. For example, Chapell et al. (2005) assessed students' test anxiety levels through self-report before, during, and after testing. The results showed that there was a significant inverse relationship between severity of test anxiety and overall undergraduate and graduate grade point average (GPA). Clearly, test anxiety has been shown to have a negative impact on academic functioning for college students; however, little is known about how to effectively treat this group. One might intuitively believe that mindfulness practice could prove to be a useful intervention in reducing test anxiety, although little to no research has been conducted to date to assess this hypothesis.

Mindfulness has been defined as one's ability to bring their attention to the experience of the present moment with non-judgmental awareness (Kabat-Zinn, 1990). According to Marsha Linehan (2014), "Mindfulness is the act of consciously focusing the mind in the present moment, without judgment and without attachment to the moment. A person who is mindful is aware in and of the present moment. Mindfulness is the opposite of being on 'automatic pilot' or being lost in habit" (p. 39). Mindfulness is the process of being able to experience thoughts, feelings, emotions and mental processes without getting caught up in them or overwhelmed by them. The process of mindfulness helps to 
reduce the potential of becoming overwhelmed by emotions, thoughts and body sensations. Therefore, mindfulness practice would seem appropriate as a possible intervention to reduce symptoms of anxiety.

There is some evidence to support the use of mindfulness-based interventions in college counseling centers to reduce symptoms of a number of mood disorders (Byrne, Bond, \& London, 2013). In fact, mindfulness has been shown to be an effective intervention for anxiety and other clinical disorders (Horman, Sawyer, Witt, \& Oh, 2010). Research on mindfulness has shown that mindfulness practices and training help reduce anxiety (Hofmann et al., 2010). Dialectical Behavior'Therapy (DBT) is a skills therapy that has been shown to help reduce clinical levels of anxiety (Gratz, Tull, \& Wagner, 2005). Most research incorporating DBT's mindfulness skills have been associated with clinical levels of anxiety, however, Nasizadeh, Babapour, and Moheb (2015) studied DBT's skills (Emotion Regulation, Distress Tolerance and Mindfulness) on high school students ( $N=412$, all females) with high achievement anxiety. Results showed that the DBT intervention effectively reduced test anxiety in high school females. However, research is still limited in regards to the implementation of mindfulness practice to reduce anxiety, in particular test anxiety.

It is clear that prior research has demonstrated the efficacy of mindfulness practice, specificallyDBT skills have been effective in reducing symptoms of anxiety. More research is needed to determine the efficacy of specifically utilizing DBT mindfulness skills to reduce test anxiety symptoms. Therefore, the aim of this study was to examine the feasibility and acceptability of how a regimented mindfulness practice may influence overall anxiety symptoms, and more specifically, testanxiety symptomatology. In addition, we examined levels of mindfulness through two differentvalidated mindfulness scales.

\section{METHODS}

Sixteen students (male $n=7$, female $n=9$, average age in years $=19$ ) in a general psychology class were recruited to participate in the study. Participants were recruited by asking the class if any one that felt they suffered from test anxiety would like to possibly volunteer for a "mindfulness for test anxiety" study. Student volunteers were assessed using the Test Anxiety Inventory (TAI; Spielberger, 1980). Those that reported having high test anxiety (2 SD above average) on the TAI were recruited for the study. During orientation (week 1) all volunteers signed written consents to participate in the study. Participants were not compensated for their participation. No students withdrew from this study. This study was approved by the local university Institutional Review Board.

The facilitator has been teaching DBT skills and mindfulness skills for approximately 10 years. The mindfulness facilitatoris a DBT intensively trained (Behavioral Tech) therapist and has an active mindfulness practice of their own. However, we do feel that these skills could be taught by others that are not DBT intensively trained and that the skills themselves are very user friendly to individuals who do not have a deep understanding of mindfulness.

Two weeks prior to the study, the experimenter recruited possible volunteers for a study on using mindfulness with test anxiety. Sixteen of the 20 potential volunteers qualified as being "test anxious," (i.e., scored two standard deviations above the norm on the TAI). Four student volunteers did not qualify as being "test anxious." Students that qualified were notified the following week, and an eight-week training schedule was established (see intervention section below, Figure 1), with sessions lasting approximately one hour each week. Each session opened with a discussion about how individual mindfulness practice was going for each participant. In addition, the group facilitator helped participants' problem-solve any barriers to mindfulness practice completion outside of session. Next, a different DBT mindfulness skill was taught each week, followed by a brief discussion on how these skills could be used in respect to the students' symptoms of test anxiety. Each session closed with a formal mindfulness practice. Participants were administered the 
TAI, Five Facets of Mindfulness Questionnaire Short Form (FFMQ SF), and the Mindfulness Attention Awareness Scale (MAAS; see Measures section below) during orientation, the fourth week (mid-way point), and again during the debriefing session at week eight.

\section{MEASURES}

The study used four self-report questionnaires to assess constructs of test anxiety, general anxiety, and mindfulness. The TAI (Spielberger, 1980) is a 20-item questionnaire that gives an overall assessment of test anxiety with two subscales: Worry and Emotionality. The TAI uses a four-point scale: (1) Never, (2) Sometimes, (3) Often, (4) Almostalways. Participants rated questions such as "I feel calm," "I feel tense," and "I feel indecisive," depending on how they felt at that moment. The TAI has shown both strong internal consistency ranging from .86 to .95 and test-retest reliability ranging from .65 to .72 (Spielberger, Gorsuch, Lushene, Vagg, \& Jacobs, 1983). Construct and concurrent validity of the scale range from .69 to .89 (Spielberger, 1989). According to Chapell et al., 2005), the TAI is one the most widely used assessments for the measurement of test anxiety in college students.

The State-Trait Anxiety Inventory (STAI; Spielberger, 1983) is a 40-item questionnaire that gives an overall assessment of general anxiety with two subscales: State anxiety and Trait anxiety. The STAI uses a four-point scale to assess State anxiety: (1) Not at all, (2) Somewhat, (3) Moderately So, (4) Very Much So and a four-point scale to assess Trait anxiety: (1) Almost never (2) Sometimes (3) Often (4) Almost always. The STAI has shown both strong internal consistency and test-retest reliability ranging from .78 to .83 for trait anxiety and ranging from .69 to .76 for state anxiety (Barker, Wadsworth, \& Wilson 1976).

The Five Facets of Mindfulness Questionnaire Short Form (FFMQ-SF; Bohlmeijer, Klooster, Fledderus, Veehof, \& Baer, 2011) is a 24-item short form of the FFMQ (FFMQ-SF) that provides measurements of five facets of mindfulness (Non React, Observe, Act with Awareness, Describe, and Non-Judge) and was developed and assessed in the same sample and cross-validated in an independent sample. Confirmatory factor analyses showed that it was an acceptable model that fit with a correlated five-factor structure of the original FFMQ and is a good model fit for the structure of the FFMQ-SF. Studies show that the FFMQ and FFMQ-SF are highly sensitive to change (Bohlmeijer et al., 2011). According to Bohlmeijer, Klooster, Fledderus, Veehof, and Baer(2011), both the FFMQ and the FFMQ-SF are reliable and valid instruments for use in adults with clinically relevant symptoms of depression and anxiety.

The Mindfulness Attention Awareness Scale (MAAS; Brown \& Ryan, 2003) measures differences in trait mindfulness by using a Likert scale asking participants to rate eachitem on a scale of 1 (almostalways) to 6 (almostnever). A total score is calculated by summing the total of each rating. An example statement is, "I find myself preoccupied with the future or the past." Total scores may range from 15 to 90, with higher scores indicating greater self-awareness. Internal consistency reliability was good with Cronbach's alpha reported at .79 for our study. 


\section{INTERVENTION}

\section{Week 1: Orientation}

During the first week, participants met with the mindfulness instructor and filled out a demographic questionnaire. The STAI (Speilberger, 1983), the FFMQ-SF (Bohlmeijer et al., 2011), and the Mindfulness Attention Awareness Scale (Brown \& Ryan, 2003) were also filled out during the orientation. Participants did not fill out anotherTAI since they had filled one out to qualify for the study; this survey was used as theirstarting point for test anxiety assessment. During the week one meeting students were oriented to what was expected of them in the study, and an eight-week schedule of different mindfulness practices were provided (see Figure 1 below for a two-week example).

Participants were also informed about DBT's mindfulness "What" and "How" skills. In addition, they learned how these skills would be taught as a means to help reduce anxiety symptoms; in particular, test anxiety symptoms overa sixweek period. Finally, they were informed that they would be given a debriefing session with an opportunity to ask questions about the study during the final week (week 8). At the end of the orientation session, the students participated in a guided 10-minute sitting meditation (Kabat-Zinn, 1994) with the group facilitator. Students were given access to other meditation practices to utilize on their own throughout the week and a mindfulness log to fill out each day when they completed (or did not complete) the assigned mindfulness practices.

Week 1 (Introduction): 4 x (10 minute sitting meditations), 1 x (Body Scan), 1 x (20 min - Mountain Meditation)

\begin{tabular}{|c|c|c|c|c|c|c|c|}
\hline WEEK 1 & Monday & Tuesday & Wednesday & Thursday & Friday & Saturday & Sunday \\
\hline $\begin{array}{l}\text { Mindfulness } \\
\text { Practice }\end{array}$ & $\begin{array}{l}\text { Sitting } \\
\text { Meditation } \\
(10 \mathrm{~min})\end{array}$ & $\begin{array}{l}\text { Sitting } \\
\text { Meditation } \\
(10 \mathrm{~min})\end{array}$ & Body Scan & $\begin{array}{l}\text { Sitting } \\
\text { Meditation } \\
(10 \mathrm{~min})\end{array}$ & $\begin{array}{l}\text { Sitting } \\
\text { Meditation } \\
(10 \mathrm{~min})\end{array}$ & & $\begin{array}{l}\text { Mountain } \\
\text { Meditation }\end{array}$ \\
\hline Completed & & & & & & & \\
\hline
\end{tabular}

Week 2 (Observe): 3 x (10 minute sitting meditation), 1 x (20 minute sitting meditation), 1 x (Body Scan), 1 x (20 min Lake Meditation)

\begin{tabular}{|l|l|l|l|l|l|l|l|}
\hline WEEK 2 & Monday & Tuesday & Wednesday & Thursday & Friday & Saturday & Sunday \\
\hline $\begin{array}{l}\text { Mindfulness } \\
\text { Practice }\end{array}$ & $\begin{array}{l}\text { Sitting } \\
\text { Meditation } \\
(10 \mathrm{~min})\end{array}$ & $\begin{array}{l}\text { Sitting } \\
\text { Meditation } \\
(10 \mathrm{~min})\end{array}$ & Body Scan & $\begin{array}{l}\text { Sitting } \\
\text { Meditation } \\
(20 \mathrm{~min})\end{array}$ & $\begin{array}{l}\text { Sitting } \\
\text { Meditation } \\
(10 \mathrm{~min})\end{array}$ & $\begin{array}{l}\text { Lake } \\
\text { Meditation }\end{array}$ & \\
\hline Completed & & & & & & & \\
\hline
\end{tabular}

Figure 1. Mindfulness schedule: First two weeks of mindfulness practices and homework. 


\section{Week 2-7: WHAT and HOW skills}

Each week a different DBT mindfulness skill was taught to the participants followed by a discussion of how the skill could specifically be used to reduce test anxiety. In addition, mindfulness practice compliance was ensured by requiring all participants to attend a face-to-face meeting each week to discuss their mindfulness practice homework and problemsolve any barriers or issues to homework completion.

Weeks 2-4: The DBT “What" skills were taught: Observe, Describe and Participate. At the end of week four, a midpoint assessment was conducted with the same surveys that were filled out during orientation (i.e. TAI, STAI, FFMQ$\mathrm{SF}$, and MAAS).

Weeks 5-7: The DBT “How” skills were taught: Non-Judgementally, One-Mindfully, and Effectively.

\section{Week 8}

Debriefing and final assessments (i.e., TAI, STAI, FFMQ-SF, and MAAS).

At the end of each session, the group participated in a short mindfulness practice.

\section{RESULTS}

Data from the surveys were analyzed in order to determine if a mindfulness intervention using DBT's "What" and "How" skills helped reduce test anxiety, overall anxiety, and increased self-report measures of mindfulness. Table 1 reports means and standard deviations for all scales included. 
TABLE 1

Means and Standard Deviations

\begin{tabular}{|c|c|c|c|c|c|c|}
\hline \multirow{2}{*}{ Measure } & \multicolumn{2}{|c|}{ Start (0 weeks) } & \multicolumn{2}{|c|}{$\begin{array}{l}\text { Mid-Point }(4 \\
\text { weeks) }\end{array}$} & \multicolumn{2}{|c|}{ Final (8 weeks) } \\
\hline & $M$ & $S D$ & $M$ & $S D$ & $M$ & $S D$ \\
\hline TAI Total ${ }^{* *}$ & 56.00 & 11.47 & 46.94 & 11.21 & 37.56 & 9.98 \\
\hline $\begin{array}{l}\text { TAI } \\
\text { Emotion** }\end{array}$ & 20.94 & 4.46 & 17.88 & 4.54 & 14.37 & 4.18 \\
\hline $\begin{array}{l}\text { TAI } \\
\text { Worry** }\end{array}$ & 19.81 & 6.37 & 17.44 & 4.13 & 13.88 & 3.99 \\
\hline $\begin{array}{l}\text { STAI } \\
\text { Overall** }\end{array}$ & 99.62 & 17.93 & 88.00 & 5.91 & 75.75 & 18.70 \\
\hline $\begin{array}{l}\text { State } \\
\text { Anxiety** }\end{array}$ & 49.31 & 10.56 & 42.69 & 3.07 & 32.25 & 9.66 \\
\hline $\begin{array}{l}\text { Trait } \\
\text { Anxiety* }\end{array}$ & 50.31 & 10.54 & 44.81 & 3.97 & 40.50 & 10.37 \\
\hline $\begin{array}{l}\text { FFMQ } \\
\text { Non-React* }\end{array}$ & 13.44 & 3.54 & 14.19 & 3.62 & 16.75 & 3.22 \\
\hline $\begin{array}{l}\text { FFMQ } \\
\text { Act with } \\
\text { Awareness* }\end{array}$ & 16.56 & 2.39 & 15.75 & 3.96 & 18.69 & 3.26 \\
\hline $\begin{array}{l}\text { FFQM } \\
\text { Describe* }\end{array}$ & 16.56 & 4.69 & 18.13 & 4.29 & 19.63 & 4.94 \\
\hline $\begin{array}{l}\text { FFMQ } \\
\text { Non-Judge* }\end{array}$ & 13.44 & 3.84 & 15.88 & 4.50 & 16.81 & 4.51 \\
\hline $\begin{array}{l}\text { FFMQ } \\
\text { Observe }\end{array}$ & 14.19 & 2.86 & 13.50 & 4.49 & 14.56 & 3.01 \\
\hline MAAS* & 53.44 & 9.23 & 55.69 & 10.42 & 62.00 & 10.74 \\
\hline
\end{tabular}

$* p<.05 . * * p<.01 . * * * p<.001$.

A within-group repeated measures ANOVA was used to assess mindfulness training on overall test anxiety and on the test anxiety subscales of Emotionality and Worry. There was a significant effect of mindfulness training on decreasing overall test anxiety, Wilks' Lambda $=17.12, F(15,2)=30.01, p<.0001, \eta^{2}=.65$, on Emotionality, Wilks' Lambda $=48.61, F(15,2)=24.30, p<.0001, \eta^{2}=.60$, and Worry, Wilks' Lambda $=17.18, F(15,2)=8.56, p=.001, \eta^{2}$ $=.48$.

A within-group repeated measures ANOVA was used to assess mindfulness training on overall anxiety and on the anxiety subscales of State and Trait anxiety. There was a significant effect of mindfulness training on decreasing overall anxiety, Wilks' Lambda $=28.73, F(15,2)=14.37, p<.0001, \eta^{2}=.55$. There was also a significant effect of mindfulness 
training on decreasing state anxiety, Wilks' Lambda $=28.13, F(15,2)=14.07, p<.0001, \eta^{2}=.64$ and decreasing trait anxiety Wilks' Lambda $=15.73, F(15,2)=7.87, p=.002, \eta^{2}=.42$.

A within-group repeated measures ANOVA was used to assess mindfulness training on the Five Facets of Mindfulness: Non-React, Observe, Act with Awareness, Describe, and Non-judge. The authors of FFMQ do not recommend using a total score of mindfulness from the FFMQ (Baer, Smith, Hopkins, Krietemeyer, \& Toney, 2006); therefore, we only assessed the five facet scores. There was a significant effect of mindfulness training on increasing mindfulness self-report ratings on Non-React, Wilks' Lambda $=14.24, F(15,2)=7.12, p=.003, \eta^{2}=.43$, Act with Awareness, Wilks' Lambda $=22.76, F(15,2)=11.38, p=.0002, \eta^{2}=.34$, Describe, Wilks' Lambda $=13.02, F(15,2)=$ $6.51, p=.0045, \eta^{2}=.30$, and Non-Judge, Wilks' Lambda $=11.40, F(15,2)=5.70, p=.008, \eta^{2}=.37$.

There was no significant effect of mindfulness training on the Observe scale.

A within-group repeated measures ANOVA was used to assess mindfulness training (IV) on (DV) overall mindfulness as rated by the Mindfulness Attention Awareness Scale. There was a significant effect of mindfulness training on increasing mindfulness rating on the MAAS, Wilks' Lambda $=14.14, F(15,2)=7.07, p=.003, \eta^{2}=.39$.

\section{DISCUSSION}

The present study investigates the feasibility and efficacy of dialectical behavior therapy (DBT) mindfulness skills to reduce test anxiety in college students on a small sample of college students that self-report as test anxious. These findings suggest evidence that participation in a mindfulness training informed by DBT's "What" and "How" skills is potentially effective in reducing both test anxiety and overall anxiety levels in college students. Interestingly, there were no changes on the Observe scale. It is possible that there were not significant changes in the Observe scale due to a ceiling effect with already anxious people, which has been previously reported in the literature (Bohlmeijeret al., 2011). It is possible that for individuals who experience high levels of anxiety with observations of their environment, the observations they have are already salient cues. For example, one of the FFMQ Observe questions addresses paying attention to physical experiences, if someone is already anxious, physical sensations could stand out far more for them than for individuals who do not experience elevated levels of anxiety. It is important to note that the individuals in the present study all met criteria for being "test anxious" (i.e., scored two standard deviations above the norm on the TAI), thus possibly skewing Observe scores of the FFMQ. However, all other scales showed a significant change and demonstrate that the participants increased overall levels of mindfulness after completing the groups.

The implications for these results suggest that mindfulness training can be an effective tool for working with college students to increase mindfulness, which, in turn may decrease overall anxiety and test anxiety through regimented training. It is recommended that college student counseling centers consider implementing a regimented mindfulness training program for students and utilize the described assessment measures to examine results of these programs.

According to Speilberger and Vagg's theory (1995), due to interpersonal cognitions and cognitions of information processing trait anxiety is exacerbated by the state of test taking, which produces test anxiety. DBT's mindfulness skills seem to be effective in treating not only generalized anxiety, but also test anxiety. The results of this study suggest that in regards to effectively coping with high levels of anxiety, DBT's mindfulness trainings may be beneficial if used in counseling centers as a coping mechanism for students experiencing high levels of test anxiety. These skills could also be utilized in high schools to help students effectively cope with test anxiety before reaching college.

The present study has several limitations. First, the scales used were self-report measures which could have skewed results from over or under reporting; however, this is common in assessment of test anxiety and mindfulness. Another 
potential limitation includes compliance with the ascribed mindfulness regiments. To counter this concern, a reported $92 \%$ compliance rate of mindfulness practice completion, results of significant decreases on both test anxiety and overall anxiety, and the significant increases of mindfulness on both mindfulness scales would suggest that deception of mindfulness practice was not occurring in this sample. This study was also voluntary and no secondary gains were offered, which would also suggest that deception was not occurring on matters of self-report. It should also be noted that this one group design does offer threats to internal validity. This study did not match this group with a wait-list control group, and it is suggested that future studies implement a wait-list control group. It is also recommended that randomized control trials and other outcome measures are examined, such as GPA.

\section{CONCLUSION}

In spite of these limitations, the present study makes important contributions to the literature on test anxiety and mindfulness. It is the first to design a mindfulness regime that could be followed with weekly mindfulness practices for students to reduce test anxiety to our knowledge. It is also the first to examine the effects of teaching DBT's "What" and "How" mindfulness skills to college students with test anxiety. Finally, it is the first to provide evidence that DBT's mindfulness skills may extend to be an effective intervention for reducing college student test anxiety. Future studies should attempt to assess differences between a treatment and control group in anxiety and mindfulness scores. In addition, future research might examine follow-up data to assess any lasting effects of the mindfulness intervention. Finally, it may prove useful to assess the effect of this intervention on actual test scores and academic performance using GPA. The present results are only a first step in examining the effects of mindfulness training on test anxiety and overall anxiety. Hopefully, the results will encourage more empirical research on mindfulness trainings and how it may benefit students with test anxiety. 


\section{REFERENCES}

Baer, R. A., Smith, G. T., Hopkins, J., Krietemeyer, J., \& Toney, L. (2006). Using self-report assessment methods to explore facets of mindfulness. Assessment, 13, 27-45. https://doi.org/10.1177/1073191105283504

Barker HR, Jr., Wadsworth AP, Jr., \& Wilson W. (1976) Factor structure of the State-Trait Anxiety Inventory in a nonstressful situation. Journal of Clinical Psychology, 32, 595-598. https://doi.org/10.1002/10974679(197607)32:3<595::AID-JCLP2270320322>3.0.CO;2-7

Bohlmeijer, E., Klooster, P., Fledderus, M., Veehof, M. \& Baer, R. (2011). Psychometric properties of the five facet mindfulness questionnaire in depressed adults and development of a short form. Assessment, 18(3), 308-320. https://doi.org/10.1177/1073191111408231

Brown, K., \& Ryan, R. (2003) The benefits of being present: mindfulness and its role in psychological well-being. Journal of Personality and Social Psychology, 84, 822-848. https://doi.org/10.1037/0022-3514.84.4.822

Byrne, C., Bond, L. A., \& London, M. (2013). Effects of Mindfulness-Based Versus Interpersonal Process Group Intervention on Psychological Well-Being with a Clinical University Population. Journal of College Counseling, 16(3), 213-227. https://doi.org/10.1002/j.2161-1882.2013.00038.x

Chapell, M. S., Blanding, B., Silverstein, M. E., Takahashi, M., Newman, B., Gubi, A., \& McCann, N. (2005). Test anxiety and academic performance in undergraduate and graduate students. Journal of Educational Psychology, 97(2), 268-274. https://doi.org/10.1037/0022-0663.97.2.268

Duesek, J. B. (1980). The development of test anxiety in children. In I. G. Sarason (Ed.). Test Anxiety: Theory, Research, and Applications (pp. 87-110). Hillsdale, NJ: Erlbaum.

Gratz, K.L., Tull, M.T., \& Wagner, A.W. (2005). Acceptance and Mindfulness Based Approaches to Anxiety. New York, NY: Springer.

Hofmann, S. G., Sawyer, A. T., Witt, A. A., \& Oh, D. (2010). The effect of mindfulness-based therapy on anxiety and depression: A meta-analytic review. Journal of Consulting and Clinical Psychology, 78(2), 169-183. https://doi.org/10.1037/a0018555

Kabat-Zinn, J. (1990). Full catastrophe living: Using the wisdom of your body and mind to face stress, pain and illness. New York, NY: Hyperion.

Kabat-Zinn, J. (1994). Whereveryou go, there you are: Mindfulness meditation in everyday life. New York: Hyperion.

Lang, J., \& Lang, J. (2010). Priming competence diminishes the link between cognitive test anxiety and test performance: Implication for the interpretation of test scores. Psychological Science, 21 (6), 811-819. https://doi.org/10.1177/0956797610369492

Linehan, M. (2014). DBT skills training manual, second edition. New York: Guilford Press.

Nasizadeh, J., Babapour, K., \& Moheb, N. (2015). Effectiveness of Dialectical Behavior Therapy (Distress Tolerance Skills, Mindfulness, and Regulation of Emotion) on Achievement Anxiety among High School Students. Biological Forum, 7(1), 1790-1795. 
Sarason, I. G. (1984). Stress, anxiety and cognitive interferences: Reactions to tests. Journal of Abnormal and Social Psychology, 46, 929-938. https://doi.org/10.1037/0022-3514.46.4.929

Sarason, I. G., \& Stoops, R. (1978). Test anxiety and the passage of time. Journal of Consulting and Clinical Psychology, 46, 102-109. https://doi.org/10.1037/0022-006X.46.1.102

Spielberger, C.D. (1983a). State Trait Anxiety. Mind Garden Inc., California.

Spielberger, C. D. (1989b). State-Trait Anxiety Inventory: Bibliography (2nd ed.). Palo Alto, CA: Consulting Psychologists Press.

Spielberger, C. D. (2010c). State Trait anxiety inventory. John Wiley \& Sons, Inc. https://doi.org/10.1002/9780470479216.corpsy0943

Spielberger, C.D. (1980). Test anxiety inventory: Preliminary professional manual. Palo Alto, CA: Consulting Psychologist Press

Spielberger, C. D., Gorsuch, R. L., Lushene, R., Vagg, P. R., \& Jacobs, G. A. (1983e). Manual for the State-Trait Anxiety Inventory. Palo Alto, CA: Consulting Psychologists Press.

Spielberger, C. D., \& Vagg, P. R. (1995). Test anxiety: A transactional process model. In C. D. Spielberger \& P. R. Vagg (Eds.). Test anxiety: Theory, assessment, and treatment (pp. 3-14). Washington, DC: Taylor \& Francis.

Tektas, O.Y., Paulsen, F., \& Sel, S. (2013). Test anxiety among German medical students and impact on lifestyle and substance abuse. Medical Teacher, 35(11). https://doi.org/10.3109/0142159X.2013.786813

Vitasari, P., Wahab, M., Othman, A., Herawan, T., \& Sinnadurai, S. (2010). The relationship between study anxiety and academic performance among engineering students. Procedia-Social and Behavioral Sciences, 8, 490-497.

Zeidner, M. (1998). Test anxiety: The state of the art. New York: Plenum Press.

Address author correspondence to:

John Lothes II

UNC Wilmington

School of Health and Applied Human Sciences

College of Health and Human Services

Trask Coliseum 5956

601 S. College Rd.

Wilmington NC 28403

Email: lothesj@uncw.edu 